\title{
Makro Sentetik Elyaf Takviyeli Silindirle Sıkıştırılmış Beton (SSB) Yolların Performans Değerlendirmesi
}

\author{
*Zeynep Algın, Kasım MERMERDAŞ ve M. Serhat ZEYNEPLİ \\ İnşaat Mühendisliği Bölümü, Harran Üniversitesi, Şanlıurfa, Türkiye
}

\begin{abstract}
Özet:
Dayanıklılık, ekonomik üretim ve hızlı uygulama olanağı sunan silindirle sıkıştırılmış beton (SSB) son yıllarda ülkemizde yol uygulamalarında ön plana çıkmıştır. SSB malzemesinin ileri düzeyde gelişmesi ile beraber bu uygulamaların daha yaygın hale gelmesi ülkemizin ihtiyacı olan yolların daha ekonomik ve hızlı yapılmasına olanak sağlayacaktır. Bu çalışmada, makro sentetik elyaf miktarının silindirle sıkıştırılmış betonun eğilme dayanımı, aşınma ve kayma direnci özellikleri üzerindeki etkisi araştırılmıştır. Beton hacminin $\% 0, \% 0.2, \% 0.4$ ve $\% 0.6$ oranlarında makro sentetik elyaf kullanılan numunelerin karışım oranları zemin sıkıştırma metoduna göre belirlenmiştir. Bu çalışma sonunda, \%0.4 makro sentetik elyaf orana kadar elyaf miktarındaki artışın SSB'nin eğilme dayanımını önemli ölçüde arttırdığı görülmüsştür. Ayrıca elyaf miktarındaki artışa bağlı olarak numune içerisindeki boşluk miktarı arttığından dolayı elyaf kullanımının SSB'nin aşınma direncini azalttığı belirlenmiştir. Numune yüzeyindeki elyaflar sürtünmeyi azalttığından kaymaya karşı direncin de elyaf miktarı arttıkça azaldığı gözlemlenmiştir.
\end{abstract}

Anahtar kelimeler: Silindirle sıkıştırılmış beton, makro sentetik elyaf, eğilme dayanımı, aşınma ve kayma direnci

\section{Performance Assessment for Macro Synthetic Fibre Reinforced Roller Compacted Concrete (RCC) Pavements}

\begin{abstract}
:
In our country, roller compacted concrete (RCC), which provides durability, economic production and rapid implementation, has come to the forefront for road applications in recent years. With the advancement of RCC as a material these practices become more widespread, the roads that our country needs will be made more economical and faster. In this study, the effect of macro synthetic fiber amount on the flexural strength, abrasion and skid resistance of roller compacted concrete (RCC) was investigated. Mixture ratios of the samples incorporating with $0 \%, 0.2 \%, 0.4 \%$ and $0.6 \%$ ratios macro synthetic fiber by volume were determined according to soil compaction method. As a result of the experimental study, it was observed that the use of $0.4 \%$ macro synthetic fibers resulted in a significant increase in the flexural strength of the RCC. Moreover it has been determined that the use of fiber reduces the abrasion resistance of RCC because the increment in the amount of fiber increases the porosity of RCC. As the fibers on the sample surface reduce the friction, it is observed that the slip resistance decreases as the amount of fiber increases.
\end{abstract}

Key words: Roller compacted concrete, macro synthetic fibre, flexural strength, abrasion and skid resistance

*Corresponding author: Address: Faculty of Engineering, Department of Civil Engineering Harran University, 63300, Sanliurfa TURKEY. E-mail address: zyilmaz@ harran.edu.tr, Phone: +904143183000 


\section{Giriş}

Konvansiyonel betona göre daha kuru kıvamda olan silindirle sıkıştırılmış beton (SSB) sıfır çökme değerine sahiptir. İsmini sıkıştırma yönteminden alan bu beton türü geleneksel beton gibi agrega, çimento, su ve gerektiğinde diğer katkı maddelerinin farklı oranlarda karıştırılması ile elde edilir. İş makinaları vasıtasıyla serildikten sonra ağır vibrasyonlu çelik tambur ve lastik silindirle sıkıştırılan bu beton türünde iyi sıkışmanın sağlanabilmesi için normal betondan çok daha yüksek bir sıkıştırma enerjisine ihtiyaç vardır [1].

SSB'nin performansı genellikle, eğilme dayanımı ve elastisite modülü gibi mekanik veya mühendislik özelliklerine göre değerlendirilir. Bununla birlikte, yollardaki taşıt hareketi, taşıt tekerleklerinin kayma ve kazıma hareketi nedeniyle yol yüzeyinde aşınma ve yıpranma meydana gelir. Bu nedenle, SSB'nin aşınma direnci yollar için çok önemli bir parametredir [2,3]. Genel olarak, herhangi bir betonun aşınma direnci, ince ve iri agreganın tipi, agrega oranı, betonun dayanımı, karışım oranı, ilave bağlayıcı malzemenin kullanımı, elyaf içeriği, kür yöntemleri ve yüzey bitirme yöntemleri gibi çeşitli parametrelerden etkilenir [4-6].

Silindirle sıkıştırılmış beton yol, rijit yol üst yapımında kullanılan sürdürülebilir ve ekonomik bir malzemedir. Silindirle sıkıştırılmış beton kullanıldığında yol yapım maliyeti, geleneksel rijit kaplamalardan veya asfalt kaplamalardan \%15-\%30 oranında daha düşük olabilir [7]. Çevresel sürdürülebilirlik açısından SSB daha düşük çimento içeriği gerektirir bu da çimento tüketimini, çimento üretimi sırasındaki $\mathrm{CO}_{2}$ emisyonunu ve karıştırma sırasında hidratasyon 1sısını büyük ölçüde azaltmaktır [8]. Öte yandan, SSB'nin düşük çekme dayanımı, yüksek rijitlik ve kuruma rötresinden dolayı çatlak oluşma olasılığı gibi bazı dezavantajları vardır [9]. Ayrıca donatı kullanılmamasından dolayı, SSB yol üzerindeki uygulanan tüm yükler, agrega kilit mekanizması ile alt tabakalara aktarılır. Gerilme çatlakları, yorulma çatlakları, yorulma hasarı, genleşme, 1sıl ve rötre çatlakları gibi etkilere yalnız beton dayanımı direnmektedir [10]. SSB'nin gevrekliğini azaltmak, sünekliğini ve eğilme direncini arttırmak ve çatlak ilerlemesini geciktirmek için lifler, polimerler ve parçalanmış atık lastikler gibi malzemeler eklenebilir [11]. Beton yolların tasarım sürecinde, betonun kalitesi basınç dayanımından ziyade dayanıklılığına, aşınma dayanımına ve eğilmede çekme dayanımına göre belirlenir [12].

SSB'nin yollarda kullanımı, düşük kayma direnci nedeniyle düşük hızlı yollarla sınırlıdır ve düz yüzey dokusundan dolayı yüksek hızlı yollarda kullanılmaya uygun değildir [13]. Yüksek hızlı yollarda kullanıldığında, kayma ile ilgili kazalarda artışa yol açacaktır [14]. Yüksek hızlı trafik yollarında kullanılması için SSB kaplama yüzeyinin üzerine ince bir aşınma tabakası yapılır [15]. Ancak, bu toplam inşaat maliyetini arttırır. Diğer bir seçenek, yüzey pürüzlülügünü ve dolayısıyla kayma direncini artıracak olan yüksek kaliteli kırma agregalarının kullanılmasıdır [16]. Güvenli ve kaygan olmayan bir yol yüzeyini garanti altına almak için uygun bir kayma direnci gereklidir [17].

$\mathrm{Bu}$ çalışmada farklı oranlarda makro sentetik elyaf kullanılarak üretilen SSB numunelerinin yollarda kullanılabilirliği açısından performans değerlendirmesi eğilme dayanımı, aşınma ve kayma direnci göz önüne alınarak yapılmıştır. 


\section{Malzeme ve Yöntem}

Bu çalışmada SSB üretimi için 0-4.75 ve 4.75-25 mm fraksiyonlarında bazalt agrega kullanılmıştır. İnce agreganın (0-4.75 mm) su emme oranı \%3 ve özgül ağırlığı 2.63 olarak, iri agreganın (4.75$25 \mathrm{~mm}$ ) ise su emme oranı \%2.46 ve özgül ağırlığ 2.74 olarak elde edilmiştir. Şekil 1'de bu çalışmada kullanılan agrega karışımına ait gradasyon eğrisi ve ACI 211.3R-02 [18] rehberinde önerilen sınır değerler verilmiştir. Ayrıca bu çalışmada özgül ağırlığı 3,17 g/ $\mathrm{cm}^{3}$ ve blaine inceliği $3430 \mathrm{~cm}^{2} / \mathrm{g}$ olan CEM-I 52.5N tipi çimento kullanılmıştır.

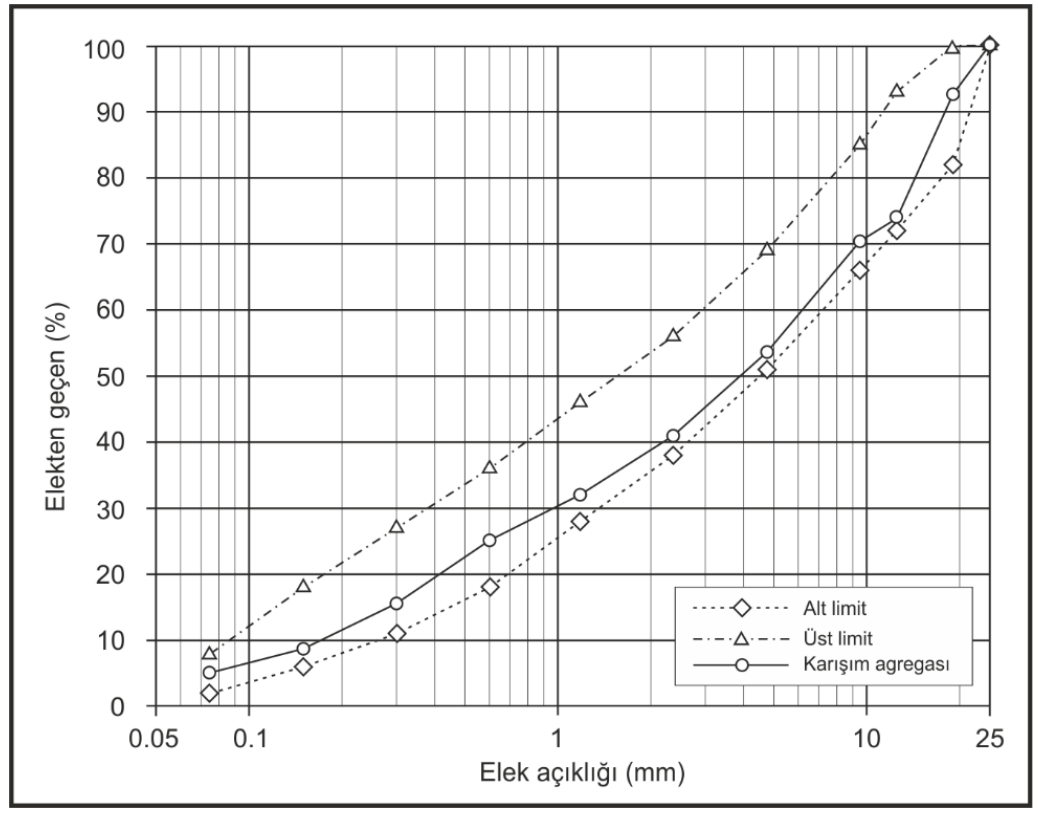

Şekil 1. Kullanılan agrega karışımına ait gradasyon eğrisi ve ACI 211.3R-02 [18] rehberinde önerilen sınır değerler

Bu çalışmada $0.677 \mathrm{~mm}$ çapında, $54 \mathrm{~mm}$ uzunluğunda ve $0.91 \mathrm{~g} / \mathrm{cm}^{3}$ yoğunluğunda makro sentetik elyaf (Şekil 2) kullanılmıştır. Makro sentetik elyaf beton hacminin \%0, \%0.2, \%0.4 ve \%0.6 oranlarında kullanılmıştır. SSB'nin karışım oranları, Amerikan Beton Enstitüsü komitesi tarafından hazırlanan çökmesi olmayan beton için karışım oranları rehberine [18] göre, maksimum kuru yoğunluğuna karşılık gelen optimum su içeriği değerinin tespit edilmesini esas alan zemin sıkıştırma yöntemi kullanılarak belirlenmiştir. Çalışmada üretilen SSB karışımlarının $1 \mathrm{~m}^{3}$ 'ü için kullanılan malzeme miktarları Tablo 1'de verilmiştir. 


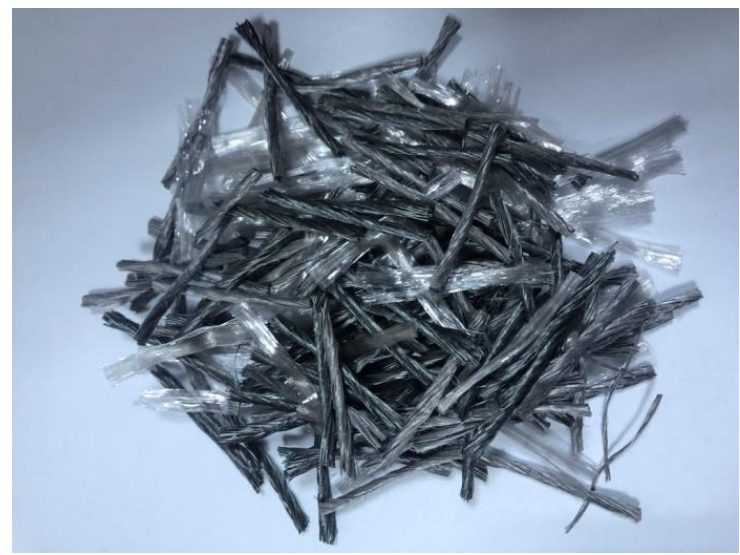

Şekil 2. Çalışmada kullanılan makro sentetik elyaf

Tablo 1. $1 \mathrm{~m}^{3} \mathrm{SSB}$ için karışım oranları

\begin{tabular}{lcccc}
\hline \multirow{2}{*}{ Malzemeler } & \multicolumn{4}{c}{ Elyaf oranı } \\
\cline { 2 - 5 } & $\mathbf{0}$ & $\mathbf{0 . 2}$ & $\mathbf{0 . 4}$ & $\mathbf{0 . 6}$ \\
\hline Çimento $(\mathrm{kg})$ & 294.67 & $294.03 \mathrm{z}$ & 293.39 & 291.49 \\
0-4.75mm agrega $(\mathrm{kg})$ & 1115.54 & 1113.10 & 1110.68 & 1103.49 \\
4.75-25mm agrega $(\mathrm{kg})$ & 989.25 & 987.10 & 984.95 & 978.57 \\
Su (kg) & 121.04 & 122.91 & 124.78 & 130.32 \\
Makro sentetik elyaf $(\mathrm{kg})$ & 0 & 4.2 & 8.38 & 12.54 \\
\hline
\end{tabular}

SSB üretiminde $40 \mathrm{dm}^{3}$ kapasiteli, düşey eksenli karıştırıcılı betonyer kullanılmıştır. Numuneler üretilirken ilk olarak agregalar ve çimento kuru olarak homojen bir karışım elde edilinceye kadar karıştırılmıştır. Daha sonra elyaf bu kuru karışıma eklenmiştir. Homojen bir kuru karışım elde edildikten sonra karışımın suyu eklenip karıştırılmıştır. Karıştırma işlemi esnasında elyafın topaklanmamasına özen gösterilmiştir. Hazırlanan karışım önceden hazırlanmış yüzeyleri yağlanmış 100x100x400 prizmatik kalıplara yerleştirilmiştir. Beton kalıplara üç kademede yerleştirilmiş ve her kademede ASTM C 1435 [19] standardına uygun darbeli çekiç yardımıyla yaklaşık 20 sn sıkıştırma işlemi uygulanmıştır. Üretilen numuneler bir gün sonra kalıptan çıkartılıp, numunelere deney gününe kadar su kürü uygulanmıştır. 28 günlük SSB numuneler üzerinde eğilme dayanımı, Böhme aşınma ve pandül deneyleri yapılmıştır.

Eğilme dayanımının belirlenmesinde 100x100x400 mm uzunluğundaki kiriş numuneler ASTM C293 [20] standardına göre 3 noktalı eğilme deneyine tabii tutulmuştur. Her karışım için üç numune üzerinde deney yapılmış ve değerlerin ortalaması alınarak eğilme dayanımı değeri tespit edilmiştir.

Aşınmaya karşı direnç TS 2824 EN 1338'e [21] göre Böhme deneyi yapılarak belirlenmiştir. Bu deneyde $71 \pm 1.5 \mathrm{~mm}$ boyutlarında küp numuneler kullanılmıştır. Numuneler etüvde $110 \pm 5{ }^{\circ} \mathrm{C}$ 'de sabit ağırlığa gelinceye kadar kurutulmuştur. Bu işlem bittikten sonra kütleleri $0.1 \mathrm{~g}$ hassasiyetle ve boyutları da $0.1 \mathrm{~mm}$ hassasiyetle ölçülüp hacimleri belirlenmiştir. Deneylerde $20 \pm 0.5 \mathrm{gr}$ zımpara tozu sürtünme yüzeyine serpilmiştir. Numunenin üzerine $294 \pm 3 \mathrm{~N}$ yük yüklenmiştir. 22 turdan 
oluşan her bir devrin sonunda otomatik olarak duran deney düzeneğinin diski temizlenip numune düşey ekseni etrafında $90^{\circ}$ çevrilmiştir. Numunenin ağırlığı deneye başlamadan ve her 4 devirden sonra ölçülmüştür. Toplam 16 devir yapıldıktan sonra numunenin boyutları ve ağırlığı ölçülerek hacim kaybı Denklem 1 kullanılarak hesaplanmıştır.

$$
\Delta V\left(\mathrm{~cm}^{3} / 50 \mathrm{~cm}^{2}\right)=\frac{\Delta m\left(\mathrm{gr} / 50 \mathrm{~cm}^{2}\right)}{\rho\left(\mathrm{gr} / \mathrm{cm}^{3}\right)}
$$

Burada:

$$
\begin{aligned}
& \Delta V=\text { Toplam hacim kaybı }\left(\mathrm{cm}^{3} / 50 \mathrm{~cm}^{2}\right), \\
& \Delta m=\text { Toplam ağırlık kaybı }\left(\mathrm{cm}^{3} / 50 \mathrm{~cm}^{2}\right) \\
& \rho=\text { Numune yoğunluğu }\left(\mathrm{gr} / \mathrm{cm}^{3}\right)
\end{aligned}
$$

Pandül deneyi kayma direncinin tespit edilmesi için ASTM E303 [22] standardına göre British pandül test cihazı kullanılarak yapılmıştır. Pandül deneyinde 100x100x400 mm boyutlarındaki kiriş numuneler kullanılmıştır. Hem kuru hem de sslak durumdaki numuneler üzerinde her iki yönde de 5 ölçüm alınmıştır. Bütün değerler okunduktan sonra iki yön için hem kuru hem de 1slak durumlardaki değerlerin ortalamaları ayrı ayrı alınmış pandül test değerleri (PTV) hesaplanmıştır.

\section{Bulgular ve Tartışma}

$\% 0, \% 0.2, \% 0.4$ ve $\% 0.6$ elyaf oranına sahip SSB numunelerin 28 günlük basınç dayanımı deney sonuçları sırasıyla, 63, 62, 59 ve $59 \mathrm{MPa}$ olarak elde edilmiştir. Bu çalışmada \%0.6 oranına kadar makro sentetik elyaf kullanımının SSB'nin basınç dayanımını önemli derecede etkilemediği ve yaklaşık \%6 oranında bir düşüşe neden olduğu görülmüştür.

Şekil 3'de SSB karışımların elyaf miktarı ile 28 günlük eğilme dayanımları arasındaki ilişki görülmektedir. En düşük eğilme dayanımı değeri kontrol numunesinde elde edilmiştir. \%0.4 oranına kadar elyaf kullanımı eğilme dayanımını kademeli bir şekilde arttırmıştır. En yüksek eğilme dayanımı değeri \%0.4 elyaf içeren numunede elde edilmiştir. Bu orandan sonra eğilme dayanımında düşüş gözlemlenmiştir. \%0.4 oranında elyaf kullanılması kontrol numunesine göre SSB’nin eğilme dayanımını yaklaşık \%15 oranında arttırmıştır. 


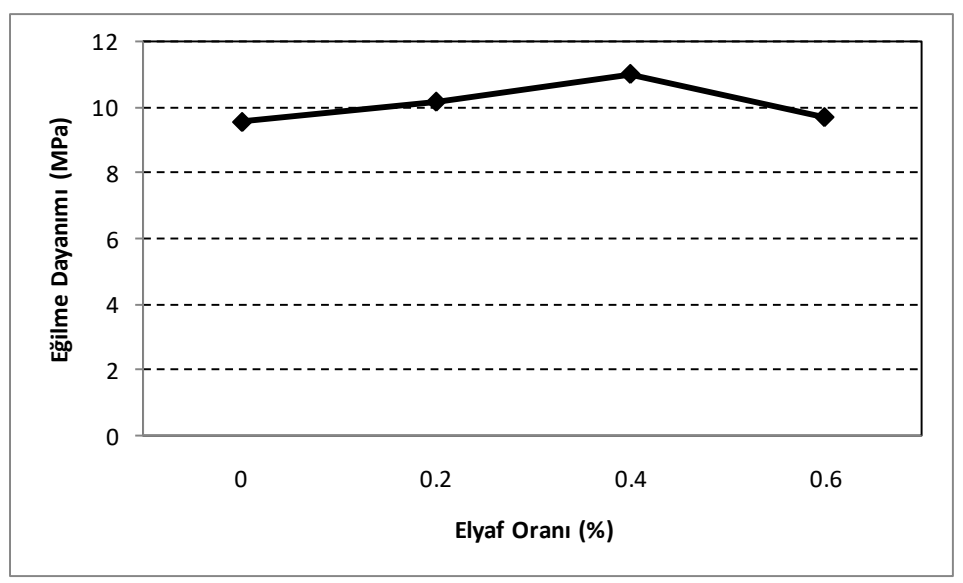

Şekil 3. SSB karışımların elyaf miktarı ile eğilme dayanımı arasındaki ilişki

Şekil 4'te SSB karışımların elyaf miktarı ile hacimsel aşınma miktarları arasındaki ilişki görülmektedir. $\% 0, \% 0.2, \% 0.4$ ve $\% 0.6$ elyaf oranına sahip SSB karışımların hacimsel aşınma kaybı değerleri sırasıyla yaklaşık olarak 13, 14, 17 ve $17 \mathrm{~mm}^{3}$ olarak elde edilmiştir. Şekil 4'te görüldüğü gibi elyaf miktarı arttıkça SSB numunelerinin hacimsel aşınma miktarı artmıştır. Elyaf miktarındaki artışa bağlı olarak elyaflar numune içerisinde topaklaşmakta ve bu da boşlukların oluşmasına sebep olmaktadır. Numune içerisinde oluşan bu boşluklar betonun aşınmaya karşı direncini düşürmektedir.

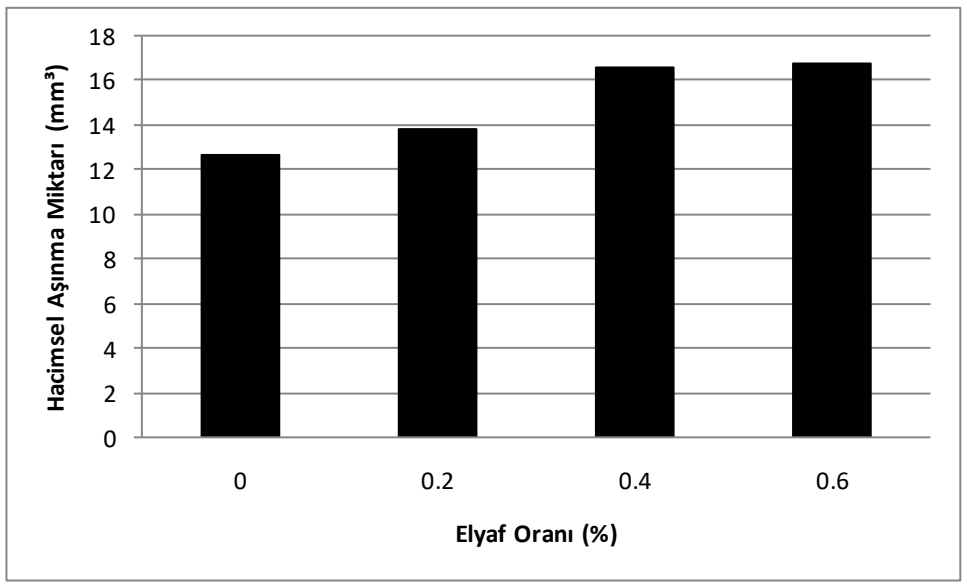

Şekil 4. SSB karışımların elyaf miktarı ile hacimsel aşınma miktarları arasındaki ilişki

Şekil 5'te SSB karışımların elyaf miktarı ile kayma direnci arasındaki ilişki görülmektedir. Kayma direncinin en yüksek değeri 69.3 ile kontrol numunesinin kuru halinde gözlemlenmiştir. En düşük PTV ise 49.6 ile \%0.6 oranında elyaf kullanılan SSB numunesinin 1slak halinde tespit edilmiştir.

PTV'ye göre kayma potansiyeli Tablo 2'de sınıflandırılmıştır. Pandül deneyi sonucunda elde edilen PTV değerleri 36'nın üzerinde olduğu için tüm SSB numunelerinin kayma potansiyeli düşüktür. PTV'ye göre kayma potansiyeli ve risk değerleri Tablo 3'de verilmiştir. Tablo 3'e göre 
deney sonuçları değerlendirildiğinde tüm numuneler düşük kayma potansiyeline sahiptir ve risk oran1 1:1,000,000'dir.

Uygulama yerlerine göre önerilen minimum PTV'ler Tablo 4'te verilmiştir. Deney sonuçlarına göre $\% 0, \% 0.2, \% 0.4$ ve \%0.6 elyaf oranları için üretilen SSB numunelerinin 1slak haldeki PTV'leri sırasıyla 62.1, 55.1, 50.4 ve 49.6'dır. Bu sonuçlara göre tüm numunelerin 1slak kayma direnci 65'in altında olduğu için bu çalışmada üretilen SSB karışımlarının kategori A'da belirtilen uygulama alanlarında kullanılmasının uygun olmadığı sonucuna varılmıştır. Kontrol ve \% 0.2 elyaf oranı ile üretilen SSB numunelerin sslak kayma direnci 55'in üstünde olduğu için bu karışımların Kategori B'de verilen uygulama yerlerinde kullanılması uygudur. \%0.4 ve \%0.6 elyaf oranına sahip numunelerin 1slak kayma direnci ise 45-55 arasında olduğu için bu karışımlar kategori C'ye uygun yerlerde uygulanabilir. Elyaf miktarındaki artış SSB'nin kayma direncini azalttığından, elyaf kullanımı SSB'lerin uygulama yerlerini sınırlandırmaktadır.

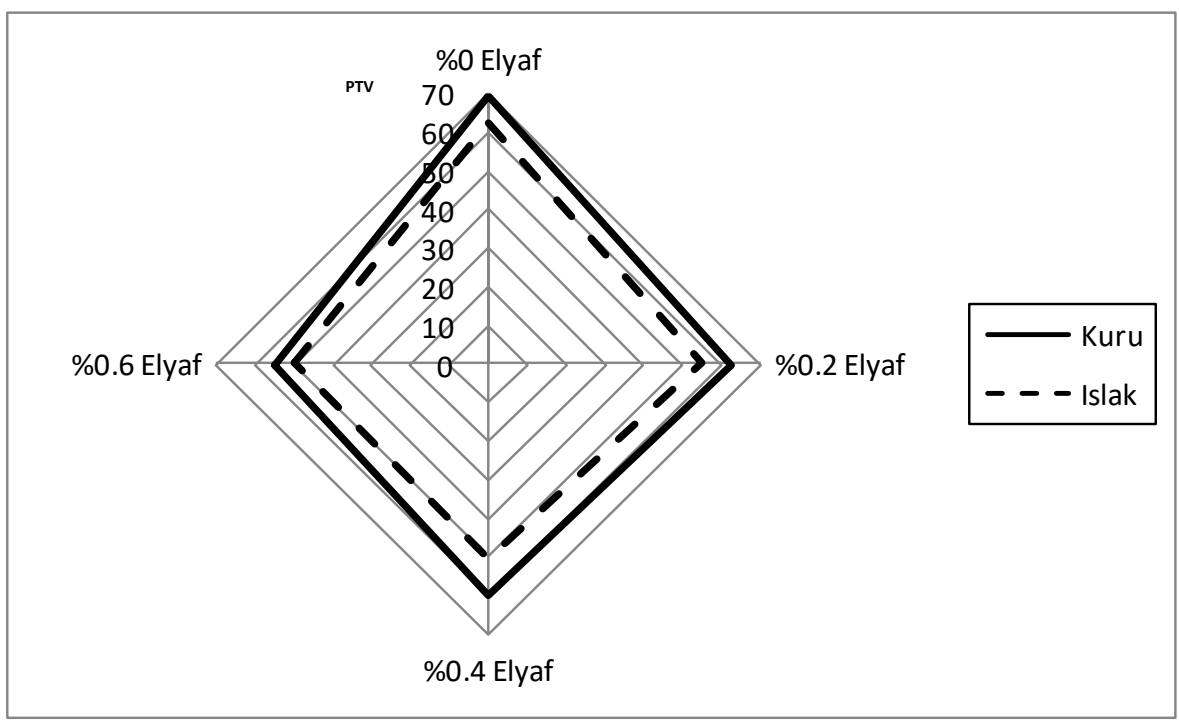

Şekil 5. SSB karışımların elyaf miktarı ile kayma değerleri arasındaki ilişki

Tablo 2. Kayma direncinin gruplandirılması [23]

\begin{tabular}{cc}
\hline Pandül Test Değeri (PTV) & Kayma Potansiyeli \\
\hline $0-24$ & Yüksek \\
$25-35$ & Orta \\
$36+$ & Düşük \\
\hline
\end{tabular}

Tablo 3. Pandül test değeri kayma riski arasındaki ilişki [23]

\begin{tabular}{lcc}
\hline Risk & Minimum PTV & Kayma Potansiyeli \\
\hline $1: 2$ & 19 & Yüksek \\
$1: 20$ & 24 & Yüksek \\
$1: 200$ & 27 & Orta \\
$1: 10,000$ & 2 & Orta \\
$1: 100,000$ & 34 & Orta \\
\hline
\end{tabular}




\begin{tabular}{lll}
\hline $1: 1,000,000$ & 36 & Düşük \\
\hline
\end{tabular}

Tablo 4. Uygulama yerine göre önerilen minimum kayma direnci değerleri [23]

\begin{tabular}{clc}
\hline Kategori & Uygulama yeri & $\begin{array}{c}\text { Minimum islak } \\
\text { Kayma Direnci }\end{array}$ \\
\hline & $\begin{array}{l}\text { Kavşaklar } \\
\text { Kısıtlanmamış yollarda yarıçapı 150 metreden az olan } \\
\text { virajlar }\end{array}$ & 65 \\
A & $\begin{array}{l}\text { Eğimi 20'de 1'den daha büyük, uzunluğu 100 m fazla olan } \\
\text { yerler }\end{array}$ & \\
& $\begin{array}{l}\text { Sinırlandırılmamış yollarda trafik 1şıklarına yaklaşımlar } \\
\text { Otoyollar, ana hatlar, 1.sınıf yollar ve kentsel alanlardaki } \\
\text { Boğun trafik taşıyan yollar(günde 2000 araçtan fazla taşıyan }\end{array}$ & 55 \\
B & $\begin{array}{l}\text { yollar) } \\
\text { Diğer bütün uygulama yerleri }\end{array}$ & 45 \\
\hline
\end{tabular}

\section{Sonuç}

Deney bulgularına göre elde edilen sonuçlar aşağıda sıralanmıştır:

1. Maksimum eğilme dayanımı \%0.4 oranında elyaf içeren numunede $11.03 \mathrm{MPa}$ olarak elde edilmiştir. Kontrol numunesine göre yaklaşık \%15'lik bir değer artışı olmuştur.

2. Aşınmaya karşı direncin en yüksek değeri kontrol numunesinde tespit edilmiştir. Elyaf miktarındaki artışa bağlı olarak elyaflar numune içerisinde topaklaşmakta ve bu da boşlukların oluşmasına sebep olmaktadır. Numune içerisinde oluşan bu boşluklar betonun aşınmaya karşı direncini düşürmekte ve toplam hacim kaybını arttırmaktadır.

3. Numune yüzeyindeki elyaflar sürtünmeyi azalttığından kaymaya karşı direncin elyaf miktarı arttıkça azaldığı gözlemlenmiştir. Elyaf miktarındaki artış SSB'nin kayma direncini azalttığından, elyaf kullanımı SSB'lerin uygulama yerlerini sınırlandırmaktadır. Pandül deneyi sonucunda elde edilen PTV değerleri 36'nın üzerinde olduğu için tüm SSB numunelerinin kayma potansiyeli düşüktür.

\section{Teşekkür}

Harran Üniversitesi Bilimsel Araştırma Projeleri Koordinasyon Birimi (HÜBAK Proje No: 18214) tarafından bu çalışma desteklenmiştir. Forta Innovative Construction firmasına makro sentetik elyaf temini konusundaki desteklerinden dolayı teşekkür ederiz.

\section{Referanslar}

[1] Harrington D, Abdo F, Adaska W, Hazaree C. Guide for roller-compacted concrete pavements. Institute for Transportation, Iowa State Univerisity, 2010; 104. 
[2] Shi ZQ, Chung DDL. Improving the abrasion resistance of mortar by adding latex and carbon fibers. Cem Concr Res 1997;27:1149-1153.

[3] Turk K, Karatas M. Abrasion resistance and mechanical properties of self-compacting concrete with different dosages of fly ash/silica fume. Indian J Eng Mater Sci 2011;18:4960.

[4] Liu TC. Abrasion resistance of concrete. ACI J Proc 1981;78:341-350.

[5] Sustersic J, Mali E, Urbancic S. Erosion-abrasion resistance of steel fibre reinforced concrete. In: Durability of Concrete. Second International Conference, August 4-9, 1991, Montreal, Canada, 126-139.

[6] Naik TR, Singh SS, Hossain MM. Abrasion resistance of high-strength concrete made with class C fly ash. ACI Mater J 1995;92:649-659.

[7] Ramezanianpour AA, Mohammadi A, Dehkordi ER, Chenar QB. Mechanical properties and durability of roller compacted concrete pavements in cold regions. Constr Build Mater 2017;146:260-266.

[8] Chhorn C, Hong SJ, Lee SW. A study on performance of roller-compacted concrete for pavement. Constr Build Mater 2017;153:535-543.

[9] Ghahari S, Mohammadi A, Ramezanianpour A. Performance assessment of natural pozzolan roller compacted concrete pavements. Case Studies in Construction Materials 2017;7:82-90.

[10] ACI 325-10R. Report on roller-compacted concrete pavements. American Concrete Institute 2001.

[11] Moghaddam TB, Karim MR, Abdelaziz M. A review on fatigue and rutting performance of asphalt mixes. Sci Res Essays 2011;6:670-682.

[12] İyinam Ş, Ağar E. Karayollarında hazır beton. Türkiye Hazır Beton Birliği, 2004.

[13] Shoenberger JE. User's guide: Roller-compacted concrete pavement (DTIC Document), 1994.

[14] Asi IM. Evaluating skid resistance of different asphalt concrete mixes. Building and Environment 2007;42:325-329.

[15] ERMCO. Guide to roller compacted concrete for pavement, 2013.

[16] Adamu M, Mohammed BS, Shafiq N, Liew MS. Skid Resistance of nano silica modified roller compacted rubbercrete for pavement applications: Experimental methods and response surface methodology. Cogent Engineering 2018;5:1452664.

[17] Chhorn C, Hong SJ, Lee SW. A study on performance of roller-compacted concrete for pavement. Construction and Building Materials 2017;153:535-543.

[18] ACI 211.3R-02. Guide for selecting proportions for no-slump concrete. Reported by ACI Committee 211, 2009.

[19] ASTM C1435. Standard practice for molding roller-compacted concrete in cylinder molds using a vibrating hammer. ASTM International, West Conshohocken, PA, 2014.

[20] ASTM C293. Standart test method for flexural strenght of concrete (using simple beam with center-point loading). ASTM International, West Conshohocken, PA, 2016.

[21] TS 2824 EN 1338. Zemin döşemesi için beton kaplama blokları-gerekli şartlar ve deney metodları. TSE, Ankara, 2005.

[22] ASTM E303. Standard test method for measuring surface frictional properties the british pendulum tester. ASTM International, West Conshohocken, PA, 2018.

[23] Nolan P. Report Number 0130-15/2. Get-a-Grip UK Limited. 2015;1-10. 